\title{
The Divergent Rates of Induced Abortion among Young Women in Finland and Denmark
}

\author{
LISBETH B. KNUDSEN, M. Sci.Soc. ${ }^{1}$
}

Danish Center for Demographic Research, University of Southern Denmark MIKA GISSLER, Ph.D., M.Soc.Sci.

Stakes, National Research and Development Center for Welfare and Health, Helsinki, Finland

\begin{abstract}
In 2000, the rate of induced abortion among teenagers was lower in Denmark than in Finland for the first time in ten years, while the abortion rate for 20-24-year-old women was lower, but increasing in Finland and decreasing in Denmark. Based on published data for 1973-2000, an analysis was made of whether the increasing abortion rates in Finland reflect an increasing occurrence of unintended pregnancies or whether there is a lower propensity to give birth if pregnant.
\end{abstract}

The findings show that the most recent increase is related both to increasing rates of pregnancies and a lower propensity to choose to give birth if pregnant, while the low abortion rates in the mid-1990s were characterized by both a decreasing rate of pregnancies and a higher propensity to give birth. Possible explanations can be found in both the reduction of the sex education programs in schools in Finland and changed living conditions for families with children.

Keywords: Induced abortion, young women, Denmark, Finland, unintended pregnancies.

\section{Introduction}

The pivot of this paper was the observation that Denmark and Finland had changed places in regard to the levels of induced abortion among 15-19-year-old women in the most recent annual statistics available. Further, the 'historical' and world-famous low teenage abortion rate in Finland had been increasing since 1995, while the rate in

\footnotetext{
${ }^{1}$ Address for correspondence: Department of Social Studies and Organization, Aalborg University, Kroghstræde 5, DK-9220 Aalborg Øst, Denmark
} 
Denmark had been at a higher level, but constantly, although slowly, decreasing since around 1990. In 2000, the rate was lower in Denmark for the first time in ten years (14.3 per 1,000 in Denmark and 14.8 per 1,000 in Finland). Regarding the slightly older group of women, the abortion rate for 20-24-year-old women was lower, although increasing, in Finland, while a constant and rather strong decrease was seen in Denmark.

The aims of the analysis presented here are to study whether the increase in the abortion rate among the young women in Finland reflects an increasing rate of pregnancies, which might mean an increase in the occurrence of unplanned/unintended pregnancies. Alternatively, the increase might be due to a lower rate of births while the pregnancy rate remains unchanged. In that case, reluctance to give birth if pregnant could be the explanation of the observed trends.

In relation to reproductive behavior and reproductive health, Denmark and Finland as well as the other Nordic countries are characterized by general sex education and dissemination of information and liberal and pragmatic views on sexuality and reproductive rights (Osler et al. 1990; Lottes and Kontula 2000). Further, safe and reliable contraceptives are easily accessible. These conditions are important factors in the development that has provided the populations with their extended possibilities of exercising effective birth control.

Regarding the prevention of induced abortion, two main strategies in the Nordic countries can be distinguished: 'primary prevention' aiming at avoiding unplanned or unintended pregnancies and a more 'indirect prevention' by policy measures aiming at influencing women to make a decision to have the child in case of an unplanned pregnancy. The latter of these two strategies might have the most direct effect on the birth rate. However, recent prevention measures have focused more on reducing the rate and the number of induced abortion in order to avoid interruption per se than aiming at an increasing birth rate (Knudsen 2002). Still, no serious attempts to limit the access to interruption have occurred in either country.

The right to pregnancy interruption, though, must still be seen in the broad perspective of the populations' efforts toward fertility control. As pointed out by Kulczycki et al. (1996), the right to interruption is necessary also in countries with a general acceptance of pregnancy planning and extensive use of contraceptives. The possibility to have an induced abortion is a last resort in case of unwanted pregnancy and, as such, one of the means to make the appreciated birth control more efficient.

One of the consequences of birth control in Denmark and Finland, as in most other Western countries, is the increasing maternal and paternal age at the birth of the first child. In the late 1990s, very few teenagers gave birth (between 7 and 11 per 1,000) and the maternal age at first birth was very close to 28 years (and the paternal age a couple of years higher) in the two countries. 
In both Denmark and Finland the laws on legally induced abortions were liberalized during the 1970s and today the populations have very similar possibilities for terminations. In Denmark, any resident woman aged 18 and over has the right to have her pregnancy interrupted on demand and at no cost to herself. The interruption has to be performed at a public hospital before the end of the 12th week of pregnancy, as calculated from the first day of the last menstrual period. Induced abortion after the 12th week requires a special permit from local municipal authorities. Interruptions are almost never performed after week 24 , although no legal upper limit is defined. If the woman is younger than 18 , custodial consent is required.

In Finland, abortion can be permitted if at least one of a number of circumstances is fulfilled, among others that the woman experiences considerable strain caused by living conditions or other conditions, or if she is younger than 17 years or older than 40 years at the time of conception. The interpretation of the abortion legislation has remained liberal. In most cases, the interruption is performed before the end of the 12th week of pregnancy (since 1978). With the permission of the National Agency for Medicolegal Affairs the interruption can be made until 20 completed weeks, except for cases with fetal abnormalities where the limit is 24 weeks (since 1985). The law recommends that the parents not be contacted if a minor aged below 18 years so wishes.

More details on the legal conditions and the registration systems can be found in Gissler (1999) and in Knudsen et al. (2003).

The low rate of induced abortion in Finland has been subject to a number of studies (e.g. Gissler et al. 1996; Kosunen 1996; Kosunen et al. 2002), while joint comparative research on the trends in induced abortion in the Nordic countries have been rare until recent years (Gissler 1999; Knudsen (ed.) 2001; Knudsen et al. 2003).

\section{Data and Methods}

The analysis covers the period 1973-2000, and is primarily based on the routinely collected data on legally induced abortions in Denmark and Finland, which have been collected since the acts on induced abortion on demand came into force in 1973 and 1970 , respectively. In both countries registration is mandatory and takes place as part of the hospitals' routine registration of their activities, while the collection, storing and publishing of data are the responsibilities of the national health authorities and/or the national statistical offices (Knudsen et al. 2003). The information on live births stems from the published, routinely collected national data in both countries (Population Statistics and Medical Birth Statistics). 
To describe the trends we use the age-specific rates of induced abortions for five-year age groups (per 1,000 women in that age group) and the general abortion rates (per 1,000 women aged 15-49 years). Further, a pregnancy rate is calculated as the sum of the abortion rate and the rate of live births, disregarding spontaneous abortions and ectopic pregnancies. The rates for 15-19-year-old women include the very few abortions and deliveries of women younger than 15 .

In both countries, age is calculated as the number of whole years the woman has reached on the day of the pregnancy termination or the delivery. Until 1993, the age of a woman having an induced abortion in Finland was calculated as the age at the end of the year. As a consequence of this, the published rates were some 10 to 15 percent lower among teenagers than if calculating the age at the date of interruption. The present analysis is based on recalculated rates of abortion using the accurate age at the date of induced abortion.

Further, to elucidate whether the trends in the rates of induced abortions are due to changes in the pregnancy rates or to a changing willingness to give birth if pregnant, an abortion proportion has been calculated. This measure expresses the number of pregnancy terminations as a percentage of the sum of induced abortions and live births. If the pregnancy rate decreases and the proportion of induced abortions is unchanged, this will be interpreted as better protection against pregnancy (e.g. by use of contraceptives, by abstention or by delaying the age of sexual debut), while the propensity to choose interruption if pregnant is considered the same. If the proportion having induced abortion decreases while the pregnancy rate is unchanged, the interpretation is that the propensity to choose having a child instead of an interruption has increased. If the abortion proportion increases, this is interpreted as a result of a decreasing propensity to choose childbirth.

The trends in rates of interruptions and pregnancies, respectively, are further elucidated by index values showing the relative change in relation to the rates in 1974 for which the index value was set at 1 .

\section{Results}

In both Denmark and Finland, the abortion rates among 15-19-year-old and 20-24year-old women have been considerably higher than the general abortion rate (15-49year-olds) throughout the study period (cf. Table 1). Moreover, the rates among 2024-year-old women have been constantly higher than the rates among the 15-19-yearold women, although the trends in the two age groups are somewhat different. 
Table 1. General rate (15-49-year-olds) and age-specific rates of legally induced abortion in Denmark and Finland since 1974. Selected years. Per 1,000 women.

\begin{tabular}{lcccccc}
\hline & & Denmark & & & Finland & \\
& $\mathbf{1 5 - 1 9}$ & $\mathbf{2 0 - 2 4}$ & $\mathbf{1 5 - 4 9}$ & $\mathbf{1 5 - 1 9}$ & $\mathbf{2 0 - 2 4}$ & $\mathbf{1 5 - 4 9}$ \\
\hline 1974 & 19,9 & 27,9 & 21,2 & 18,5 & 28,3 & 19,1 \\
1975 & 25,0 & 32,5 & 23,7 & 21,2 & 26,0 & 17,9 \\
1976 & 26,0 & 31,7 & 22,7 & 20,4 & 24,7 & 16,4 \\
1980 & 22,1 & 29,4 & 19,0 & 19,4 & 19,7 & 12,3 \\
1985 & 16,3 & 28,8 & 15,6 & 16,5 & 19,5 & 11,0 \\
1990 & 17,2 & 30,2 & 15,7 & 15,4 & 18,3 & 9,7 \\
1995 & 14,8 & 22,5 & 13,7 & 10,6 & 14,6 & 7,8 \\
2000 & 14,3 & 19,9 & 12,5 & 14,8 & 15,9 & 9,0 \\
& & & & & & \\
\hline
\end{tabular}

Source: Population statistics in the two countries

The abortion rate among 15-19-year-old women peaked in Denmark a few years after the liberal act came into force. After the peak in 1976 a strong decrease was seen till the early 1980 s, while the following years were characterized by a much slower, although constant decline. Finland started at almost the same level as Denmark in 1974 and experienced only a minimal peak in 1975. Thereafter, the teenage abortion rate declined almost constantly, but slowly, for more than ten years. From 1985 to 1988 the rate was higher in Finland than in Denmark, but during the period from 1989 to 1994 a very steep decline brought the rate in Finland to a level as low as one-third below the rate in Denmark.

However, since the mid-1990s, the low level in Finland has been replaced by an increase, while the decrease continued in Denmark. In the year 2000, the rate among teenagers in Denmark was lower than that in Finland (Figure 1 on next page).

Concerning women aged 20-24 years, the trends have been different. During the whole period the abortion rate has been higher in Denmark than in Finland, and in most of the 1980s the level in Denmark was about 50 percent higher than in Finland. Further, the rate in Denmark did not begin to decline until the early 1990s, while in Finland the overall picture has shown a continuously decreasing trend from a rate at the same level as in Denmark in the beginning of the period to the lowest point in 1994. Since then, the abortion rate has been increasing in this age group in Finland, although not as steeply as the recent increase among the 15-19-year-old women.

Inspecting the pregnancy rates demonstrates other remarkable differences between the countries. For the youngest group, those 15-19 years old, both levels and trends in the pregnancy rates are quite similar in Denmark and Finland, cf. Figure 3. Compared to Figure 1, it should be noted, though, that the pregnancy rate in Denmark was lower than in Finland for ten years (1982-1992), while the abortion rate was lower for only four years. 
Figure 1. Rates of legally induced abortion among 15-19-year-old women. Denmark and Finland, 1974-2000. Per 1,000 women.

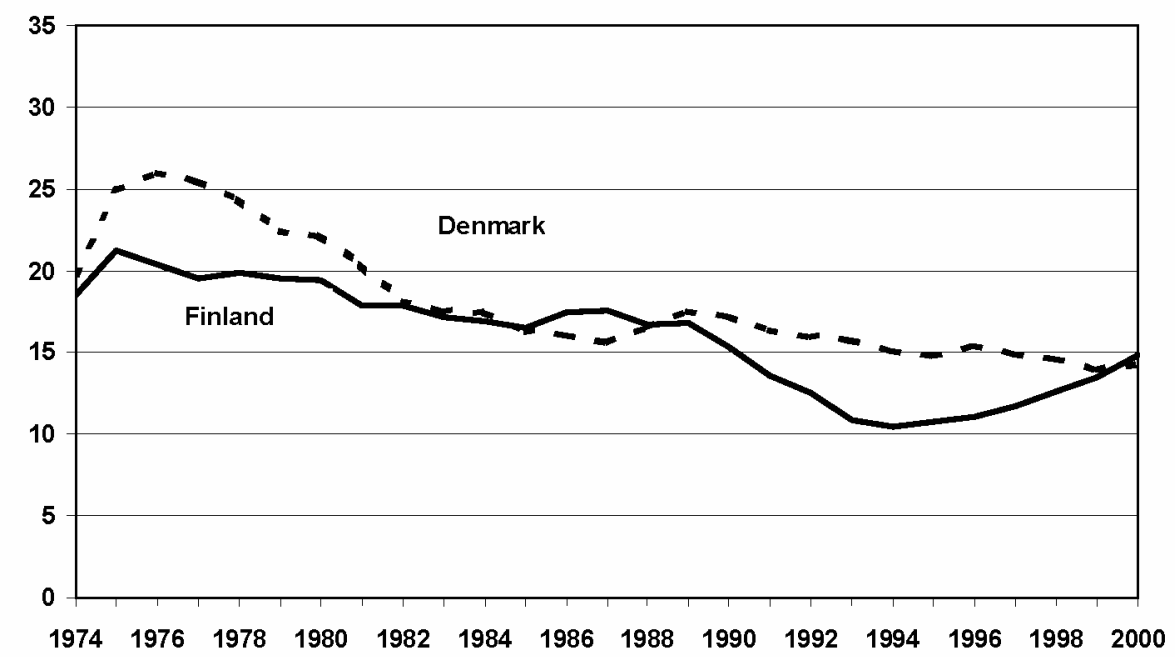

Figure 2. Rates of legally induced abortion among 20-24-year-old women. Denmark and Finland, 1974-2000. Per 1,000 women.

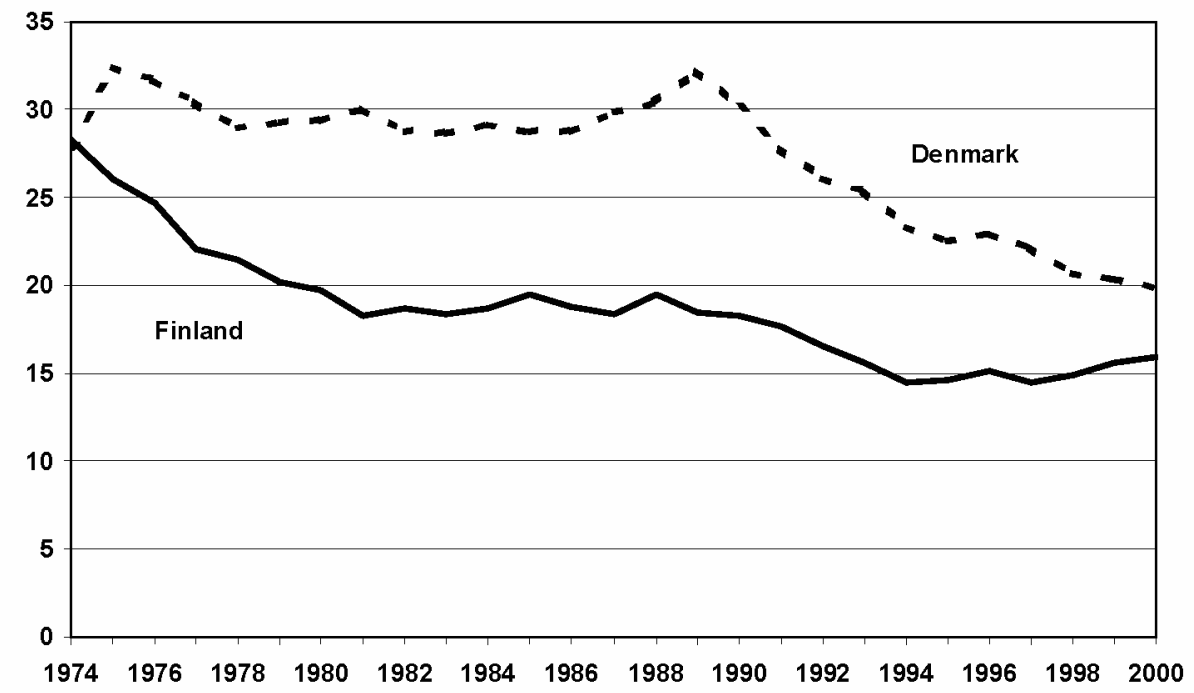


Figure 3. Pregnancy rates among 15-19- and 20-24-year-old women. Denmark and Finland, 1974-2000. Per 1,000 women.

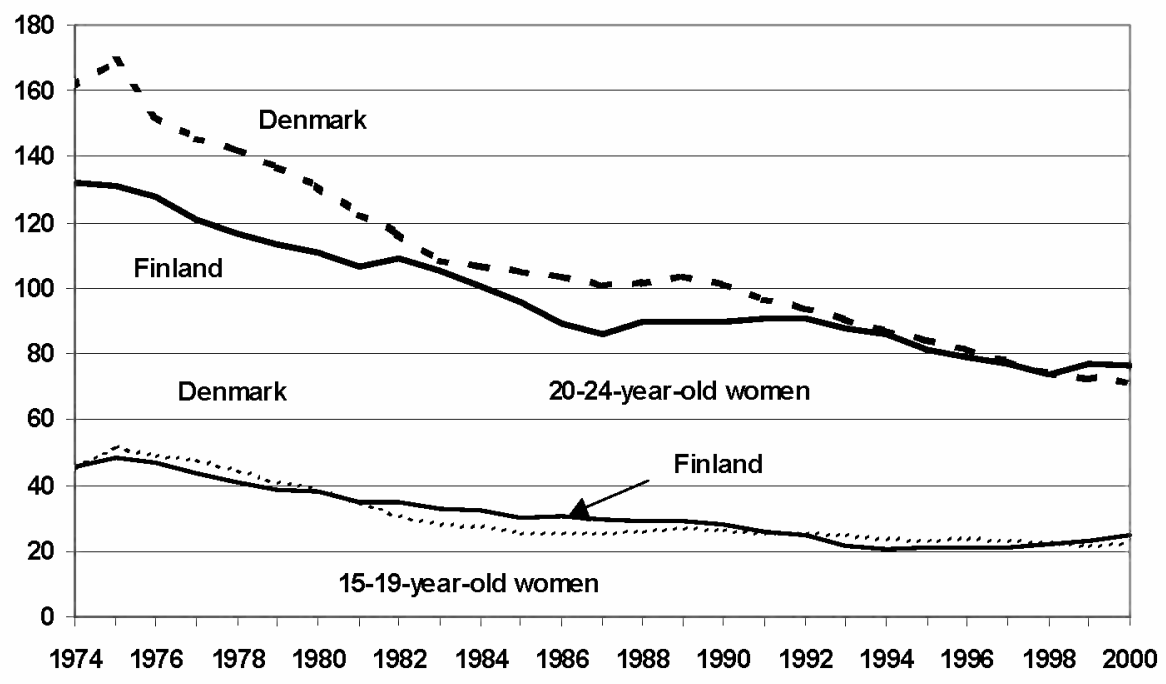

Figure 3 further reveals that the pregnancy rate in Denmark among 20-24-year-old women was remarkably higher than in Finland in the 1970s (Figure 3). The decrease in the pregnancy rate in Denmark has been almost constant and the relatively high, unchanged level seen in the abortion rate is not reflected in the pregnancy rate. Finland has had a lower pregnancy rate from the beginning and with a smoothly decreasing trend the two countries are showing almost identical pregnancy rates for the 2024-year-old women during the 1990s. However, as was the case for the 15-19-yearold women, the rate has been lower in Denmark in the most recent years for which data is available.

The comparisons of the pregnancy rates and the abortion rates indicate differences between the countries regarding the propensity to choose interruption or to give birth when pregnant. The following investigation of the abortion proportions will further elucidate this problem.

In both countries an increasing proportion of pregnant 15-19-year-old women have had their pregnancy terminated up till the mid-1980s, cf. Figure 4. Since 1983, the proportion has been rather stable in Denmark - around 64 percent - with only minor fluctuations, while Finland experienced a drop in the proportion from 60 percent to 51 percent from 1987 to 1993. In the years 1992-1994 almost half of the pregnant teenagers in Finland gave birth. The very low abortion rate in Finland in the mid-1990s can thus be related both to a decrease in the occurrence of pregnancies, which are predominantly unintended among teenagers and to an increasing propensity to give birth among pregnant teenagers. 
Figure 4. Percentage of pregnancies interrupted by legally induced abortion. Denmark and Finland, 1974-2000. Per 1,000 15-19- and 20-24-year-old women.

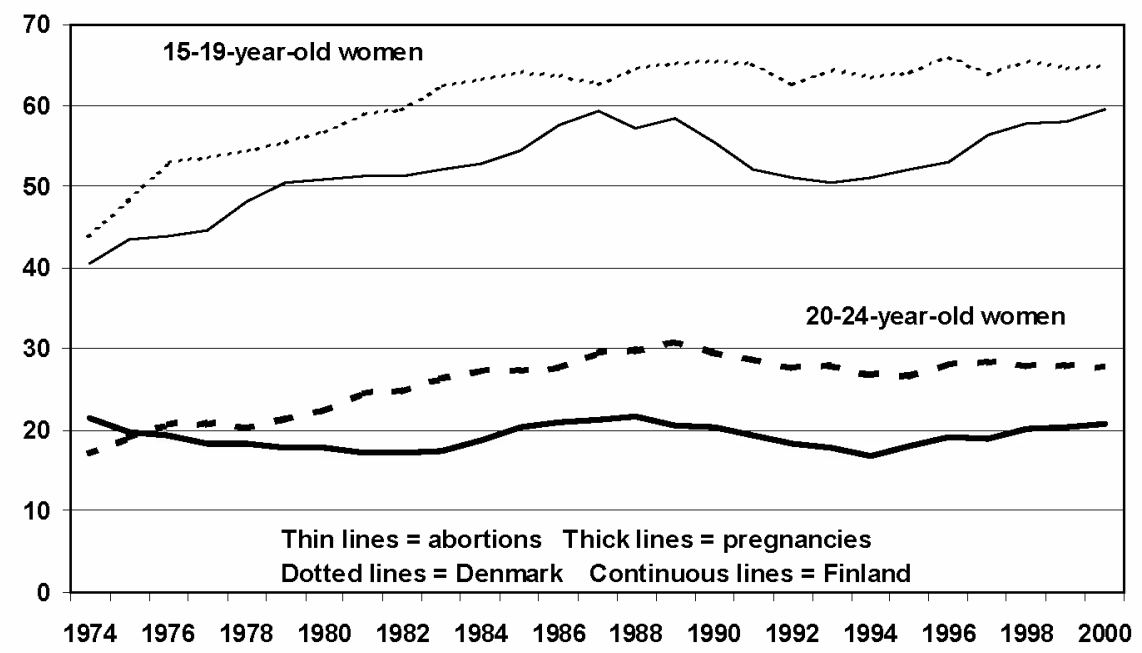

The recent increase in the abortion rate in Finland is related to an increasing proportion of teenage pregnancies being interrupted, $\mathrm{cf}$. Figure 4. In fact, the proportion of abortions is 59 percent in 2000, which is almost the same as the level in 1986 and 1987 (58 and 60 percent, respectively).

In Denmark, the abortion proportion among women aged 20-24 years has shown an almost parallel trend to the one noted for teenagers, although the increase continued until 1989. Finland started at a higher level in 1974 but showed no increase until 1983. Compared to the ups and downs in the rate for teenagers in Finland, the picture seems more stable for the 20-24-year-olds. However, the proportion among the 20-24year-old women in Finland also decreased in the early 1990s and has been increasing since the mid-1990s. The generally lower abortion proportion among 20-24-year-old women compared to the 15-19-year-olds are primarily due to the higher fertility rates in these age groups, which indicate that a higher proportion of the pregnancies in this age group are intended.

The calculated index values confirm the impression arising from an inspection of the abortion and the pregnancy rates that in both countries the declines in pregnancy rates in the 1970s and the early 1980s were steeper than the declines in the abortion rate, cf. Figure 5. For teenagers, the pregnancy rate halved from 1975 to 1985 in Denmark and decreased by more than one-third in Finland in the same period. In summary, the very low abortion rate among 15-19-year-old women in Finland in the mid-1990s can be related to a decrease in the pregnancy rate, indicating less unintended pregnancies. Further, during these same years the proportion of abortions was very low, supporting the notion that these years were characterized by an increased propensity to give birth among the youngest women. 
Figure 5. Index values of abortion and pregnancy rates per 1,000 15-19-year-old women. Denmark and Finland, 1974-2000.

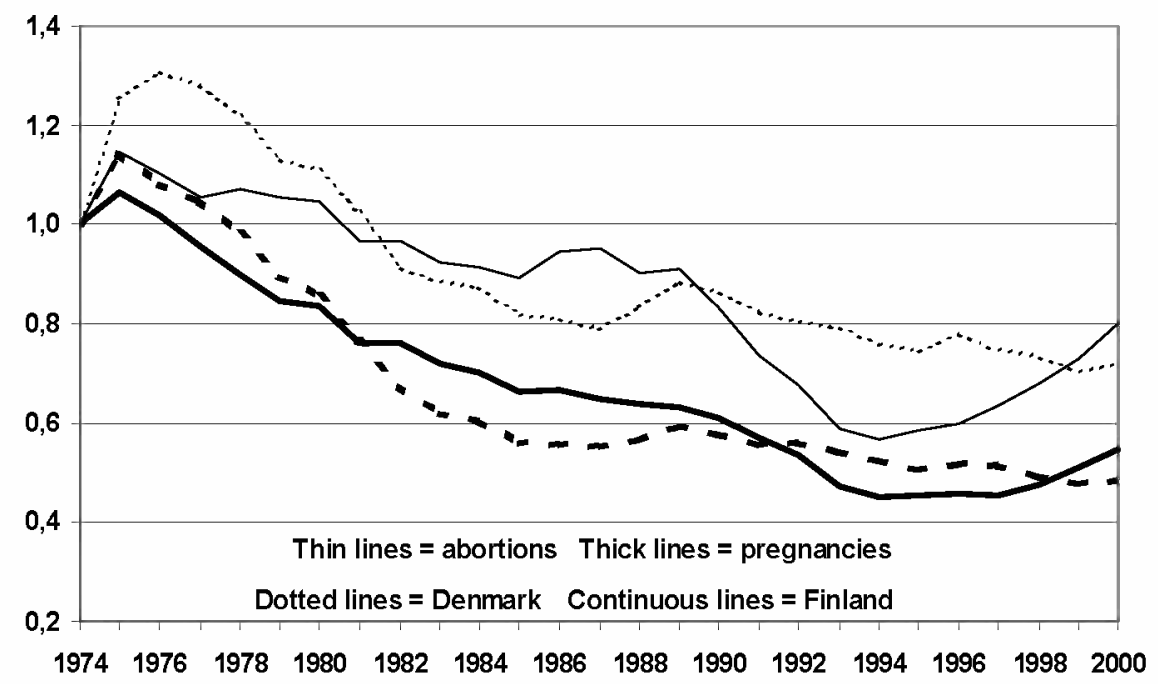

The most eye-catching difference between the countries in regard to the index values for 20-24-year-old women are considered are the different slopes of the curves, cf. Figure 6. In Denmark, the decrease is much stronger in the pregnancy rate than in the abortion rate from the beginning of the period. In Finland, the decrease is very similar in the two types of rates. This supplements the picture of the higher level of abortion proportions in Denmark (Figure 4).

Figure 6. Index values of abortion and pregnancy rates per 1,000 20-24-year-old women. Denmark and Finland, 1974-2000.

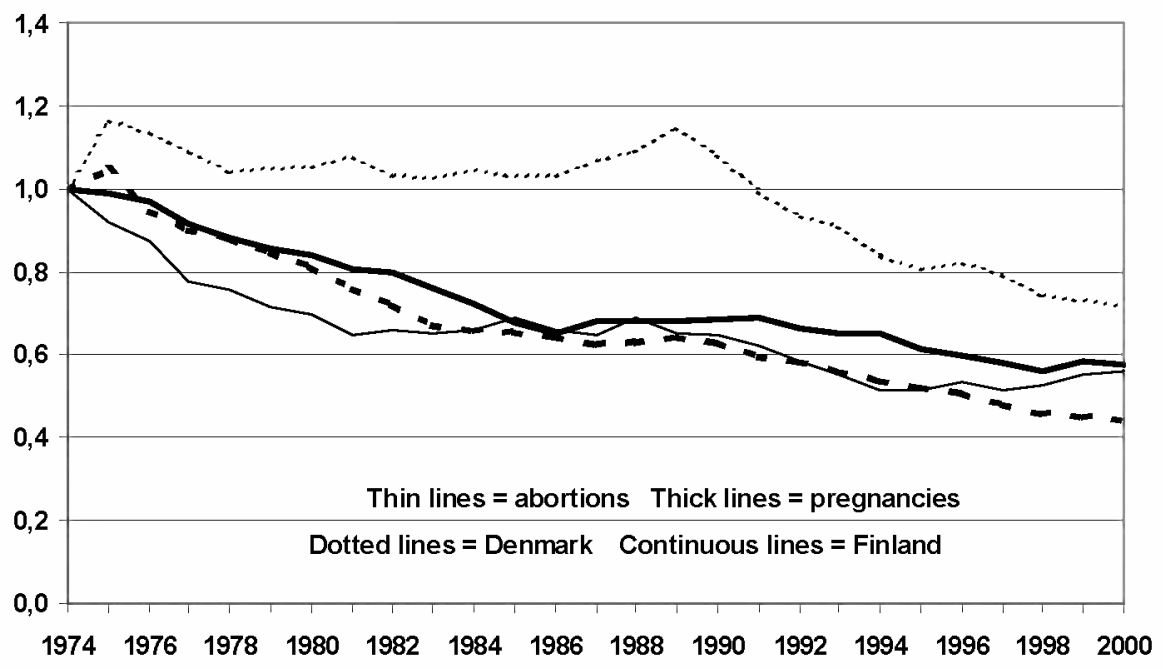




\section{Discussion}

We have studied the trends in induced abortion in Denmark and Finland since the liberal acts on pregnancy termination came into force in the early 1970s, focusing on women younger than 25 years, which is lower than the mean age of first childbirth in both countries. One of the main interests of the study was to investigate whether the changing abortion rates were related to changes in the occurrence of unintended pregnancies or to changes in the propensity to give birth if pregnant. Both the demographic impact on the birth rates and the preventive strategies will vary accordingly depending on which of these two explanations was the most convincing.

\section{Validity of data}

The sources for the study were the published national statistics on induced abortion, which are generally considered valid in both countries as they are based on mandatory registration in the hospital departments at which the abortions are performed. The completeness of the reported data is often considered most valid in cases where the registration of abortions is integrated in the electronic administrative registration routines in the hospital. Denmark introduced electronic registration in 1995, substituting specific notifications by data retrieval from the hospitals' registration systems (Krebs, Johansen and Helweg-Larsen 1997). In Finland the abortion register is collected by paper-form notifications due to the Abortion Act, which requires a signature by the physician performing the induced abortion (Gissler et al. 1996).

Further, all interruptions are performed after the pregnancy is diagnosed by ultrasound or a urine test, which gives certainty that the reported events are terminations of established pregnancies (Knudsen et al. 2003).

\section{The 15-19-year-old women}

One actual eye-catching difference between the countries was that the level of induced abortion among the young women was lower in Finland than in Denmark until the unexpected change in the very last few years which made the rate of abortions among 15-19-year-old women lower in Denmark than in Finland from the year 2000.

We applied different measures in the study, namely the age-specific rates of induced abortions and similar rates of pregnancies, calculated as the sum of live births and legally induced abortions. Further, the proportion of the pregnancies which were interrupted by induced abortion has been calculated. This approach revealed that the recent increase in the relative number of abortions must be considered not only a result of problems in the use of contraceptives. The propensity to give birth in the study period may have changed due to changed conditions for giving birth and raising children. For the 15-19-year-old women, the most recent increase in abortion rates in Finland is characterized both by an increase in the rate of pregnancies and in the proportion of 
the pregnancies that are interrupted, indicating a growing occurrence of unintended pregnancies in Finland but also a decreasing propensity to give birth if pregnant. In contrast to this, the mid-1990s with its very low rate of abortion among 15-19-yearold women in Finland was characterized by a low pregnancy rate and a higher propensity to give birth.

Comparing with development in Denmark, we did not find a similar picture among the youngest women, which points at the need to look for country-specific changes in Finland in order to explain development. Moreover, the recent findings on the teenagers in Finland indicate two facts: the occurrence of unintended pregnancies has increased among the youngest women and the wish to have a child in the late 1990s was less prevalent than in the mid-1990s. Therefore, we have to look for both changes related to contraceptive behavior and changes for families with children in Finland in the $1990 \mathrm{~s}$, as the living conditions for families with small children are expected to influence the decision-making process among couples on whether to have a(nother) child.

\section{The 20-24-year-old women}

The life situation of women in their early $20 \mathrm{~s}$ is different from that of teenagers, in that most of them are in a more stable relationship and sexually more active. Planning of births is the norm, and they are expected to know about and use contraceptives in a responsible way (Leridon 1999). Further, they are in the midst of the phase in life where they are completing their education, establishing themselves on the labor market and having to make important decisions about partnership and parenthood. Nevertheless, they will be influenced by some of the same conditions which influence the choices of the teenagers and further, some of them only left school a few years ago.

The picture among women in this age group differs from the picture among the youngest women. In both countries a higher proportion of the pregnancies are carried to term, indicating a higher degree of pregnancy planning and living conditions more suitable for childbearing. In Finland, a higher propensity to give birth is seen in the mid-1990s while this decreases in the late 1990s - parallel to the development seen among the teenagers. Both age groups seem to be influenced by some societal conditions during these years.

In Denmark the increase in the abortion proportion took place before 1990. Since then the curve has been stable, as was the case for the teenagers in Denmark.

\section{Use of contraceptives}

In both countries and especially in Finland the low abortion rate has often been attributed to the good contraceptive use among adolescents and extensive sex education in the public schools (Knudsen et al. 2003; Kosunen 1996; Mandelin 1997; Osler et al. 1990). 
The use of contraceptives is routinely registered among abortion patients in Finland. The share of abortion patients who have not used any contraceptive is largest among the youngest women, which may partly explain why the increase in the abortion rate is stronger among the 15-19-year-old women than among the 20-24-year-old women. Unpublished data from the Finnish Abortion Register shows that the percentage of abortion patients younger than 20 years, who had used no contraception in relation to the actual pregnancy, decreased from 41 percent in 1994 - the year with the low abortion rate and the low proportion of interrupted pregnancies - to 36 percent in 1997. In the following four years, the percentage of non-users increased again to 41 percent. Apparently, the women's decisions on whether to choose interruption were different in these periods as relatively more pregnant women gave birth in the mid1990 s.

Further, according to two national sex surveys carried out in 1992 and 1999, the proportion of women who reported a need of prevention and who reported use of any reliable method decreased from $92 \%$ in 1992 to $87 \%$ in 1999 . This study confirmed the somewhat poorer use of contraceptives among young Finnish women (HaavioMannila and Kontula, 2001).

In Denmark there is no routine registration of contraceptive use. However, calculations and surveys have shown that approximately half of the women undergoing abortion may have experienced contraceptive failure in the actual pregnancy (Osler 1991; Rasch, Knudsen and Wielandt 2001), and 46 percent of the women who have an abortion in a non-planned pregnancy are younger than 25 (Rasch et al. 2001). These young women were also more likely to have experienced contraceptive failure in relation to use of the condom and oral contraception than women aged 25-34 years and 86 percent of the pregnancies among women younger than 20 were unplanned (Rasch 2002).

Another possible explanation of the increasing induced abortion rates in Finland might be the recent changes in the background of the population. The population in Finland has changed in that there is an increasing number of foreigners, especially women from Russia and the Baltic states. Women from these countries have traditionally used contraceptives less frequently and had higher rates of induced abortion than the Finnish population (WHO 2002). However, a register study in Denmark covering 1994-98 showed that the abortion rates among immigrants were higher than among Danish women, but also that for most nationalities the differences were largest among women in their late 20s or even older (Ingerslev 2001). If a similar situation exists in Finland, there is no reason to expect a higher abortion rate among the youngest women due to immigration, even though the patterns differ between nationalities. The available data on induced abortion in Finland does not facilitate a continuous monitoring of the abortion rates by nationality or even country of origin due to data protection 
rules. In order to explore this hypothesis further, an ad hoc study should be conducted, combining data from the Abortion Register and the Census data collected by Statistics Finland. Such a study requires permission from the register holders and from the data protection authorities before the necessary data can be linked.

\section{Sex education}

The less extensive use of contraceptives in Finland in the most recent period might be related to the fact that the provision of school health services has become poorer due to reduced resources in the public health services, especially in preventive health services. In the large towns and cities, the school nurses are more often located at health care centers instead of the schools, which may considerably hinder young girls/ women from coming and discussing prevention and induced abortion.

Since 1994, the national curriculum for sex education in Finland has been withdrawn, and municipalities (and even individual schools) have had the right to decide on the curriculum. This has led to large differences in the quality and quantity of sex education. As a consequence, the most recent national school health surveys have confirmed large differences in the level and quality of sex knowledge between schools. Together these changes might pull in the direction of relatively more unintended pregnancies among teenagers.

The observation that the negative trend continued in Finland in 2001 with an increase in the abortion rate for girls aged 15-19 years to 15.4 per 1,000 led to two important decisions being taken to reduce the number of induced abortions among teenagers. First, emergency prevention (the morning-after pill) was made available without prescription for girls over 15 (May 2002) and health education became an obligatory subject for all school children (August 2002). However, the effect of these initiatives on the teenage abortion rate will be observed from 2002 on.

According to the Public School Act in Denmark, sex education is a compulsory topic, which should be integrated in the school subjects during the first nine years in school (Bekendtgørelse 2000). Guidelines for schoolteachers from the Ministry of Education may be supplemented by material from a number of organizations and no serious cuts or limitations like those in Finland have been seen. In recent years young girls and boys have increasingly claimed that the information they get from school is more important than that they get at home (Boelskifte, Saval and Leisgård Rasmussen 2002).

\section{Sexual activity}

The national school health survey in Finland shows that the percentage of very young women who have had their sexual debut increased during the last part of the 1990s. In the five years from 1996/97 to 2000/01 the percentage of 15/16-year-old girls who had had their sexual debut increased from 29 percent to 34 percent. At the same time, 
the percentage of young girls who have had sexual intercourse at least 10 times increased from 5 to 7 percent in the years 1996-2001 among 14-15-year-old girls and from 14 to 17 percent among the 15-16-year-old girls (STAKES 2002).

Findings from the above-mentioned national surveys (from 1992 and 1999) showed minor changes in the trends regarding sexual activity among young Finnish women during the 1990s. The first intercourse took place slightly earlier: in $199224 \%$ of women had their first intercourse before the age of 16 and $61 \%$ before the age of 18 , while these percentages increased to $27 \%$ and $69 \%$, respectively. The proportion of women with no intercourse remained stable: $23 \%$ among women aged 19 years or less, and 5-7\% among women aged 20-24 years. Young women reported no changes in the number of partners, and had intercourse some 6-7 times during the last 30 days (Haavio-Mannila and Kontula, 2001).

Unfortunately, no such routinely collected information is available for Denmark. However, the existing information on sexual activity indicates that the age at first sexual intercourse did not change considerably during the 1980s and the 1990s. Two surveys revealed that the median age at first sexual intercourse was 17 years for both sexes in 1989 (Wielandt and Knudsen 1997) and 16 years in 1997/98 (Ung99 1999). Neither of these surveys found any significant differences between women and men regarding the age of their debut. The latter survey further showed that young women (and men) with a non-Danish background became sexually active at a higher age than Danish young people (Ung99 1999).

Another Danish study (Meldbye and Biggar (1992), here quoted from Bozon and Kontula 1997) has found that the age at first sexual intercourse was lower among the younger than the older cohorts. Further, in the cohorts born in the 1930s the men were on average younger than the women when they became sexually active, while this pattern changed in the cohorts from the 1960s and 1970s where the women were younger at first intercourse. A similar changing pattern is reported from Finland (Kontula and Haavio-Mannila (1995), quoted from Bozon and Kontula 1997) and in the youngest cohorts Finnish girls are almost the same age as the Danish girls at their first intercourse (16.6 and 16.7 years, respectively), while the Finnish boys are older than the boys in Denmark (18.0 and 17.4 years, respectively).

\section{Social conditions of young families}

A recent Finnish questionnaire study indicated that the ideal timing for first childbirth is considered to be 25 years instead of the current 28 years. Among women younger than 30 , the main reasons for postponing childbearing were related to problems in reconciling education and work with pregnancy and childcare. Other important reasons not related to family policy were the feeling of being too immature to be a parent and the lack of a suitable father (Paajanen 2002). These findings are in accordance 
with Danish studies. Among women who either gave birth or had an abortion in the early 1990s approximately 65 percent said that the first child should be born when the woman was 25-29 years old (Bertelsen 1994). Both in this and in Rasch et al. (2001) the quality of the relationship with the father of the child to be born is also considered of great importance.

Some specific conditions in Finland in the early 1990s might have been influential in making the choice to give birth if pregnant. A home-care allowance was introduced in 1990, but reduced in 1994. In the early 1990s the unemployment rate increased to almost 20 percent in Finland and from 1995, the rules were changed again so that it became impossible for the same family to get both unemployment benefit and homecare allowance (Vikat 2002). Some studies have found higher birth rates in periods with unemployment and if this applies to Finland as well, this may at least partly explain the change from the mid-1990s to the late 1990s in the propensity to give birth.

A recent analysis was unable to identify any sociodemographic changes in Finland which could account for the decreasing pregnancy rate until the late $1990 \mathrm{~s}$, although the same study found some evidence in changing structures of the families of origin leading toward a higher risk of teenage pregnancy (Vikat et al. 2002). If this continues, it will most likely decrease fertility rates and increase the proportion of pregnancies ending in induced abortion among young women in Finland. Policies which generally increase the economic support for families with small children have the strongest effect on women older than 25 or the decision on whether to have a third or higher parity child (Vikat 2002). Among the youngest women, labor market policies cannot be expected to influence the propensity to give birth, as the young women very often are employed under short-term contracts (Bardy et al. 2001). Consequently, these policies are not expected to play significant roles concerning pregnancies among young women.

The rise in unemployment in the early 1990s in Finland was especially high among younger people and it may have influenced these women's wish to have their first child. If it is assumed that unemployment increases the propensity of young women to give birth, this factor might account for at least part of the low abortion proportion in the early 1990s. In Denmark, the unemployment rate among young women did not show a clear-cut increase around 1990 but reached its highest level in 1993 (13.2). In the following period, unemployment among 16-24-year-old women fell to four percent in 1999. 


\section{Conclusions}

We have found indications that reductions in the sex education programs in schools in Finland may be at least partly responsible for the recent increase in abortion rates among young women. Similar reductions have not occurred in Denmark, where the abortion rates continue to decline. In Finland poorer conditions for families with small children may also have changed the propensity to give birth if pregnant.

However, the changes in the abortion rates may also reflect ongoing cultural and behavioral changes as recent years have shown increasing rates of induced abortion among young adolescents also in Iceland and Sweden, while Norway has a slight decrease for teenagers (Knudsen et al. 2003). Further, the most recent information from the Netherlands indicates increasing rates of induced abortion among young women (NIDI 2002).

One may speculate on the reasons for this. How is the abortion rate influenced by a general acceptance of early sexual activity, of the cultural changes and of an environment which is filled with sex (advertisements, movies, TV, newspapers)? More research is needed on this topic and by use of other kinds of data than that provided by registers.

The importance of keeping a constant high standard in sex education must be underlined as there are new generations of young women and men who need sex education, including information on contraceptives.

\section{References}

Bardy, Marjatta, Minna Salmi and Tarja Heino. 2001. What threatens our children? Guidelines for child policy discussion in the 21st century, STAKES Reports 263.

Bekendtgørelse af lov nr. 730 om folkeskolen af 21.7.2000.

Bertelsen, Ole. 1994. Abort eller fodsel. [Abortion or delivery]. Copenhagen: Danish National Institute of Social Research.

Boelskifte, Jane, Per Saval, Kjeld Leisgård Rasmussen. 2002. Sexual knowledge and sources of information among ninth-grade pupils in the municipality of Viborg over the last fourteen years. Ugeskrift for Laeger 2002; 164: 3203-6 (In Danish).

Bozon, Michel and Osmo Kontula. 1997. Initiation sexuelle et genre. Comparison des évolutions de douze pays européens. Population 1997; 6: 1367-1400.

Gissler, Mika (editor). 1999. Aborter i Norden. [Induced Abortions in the Nordic Countries]. Statistical report 10. Helsinki: STAKES (National Research and Development Centre for Welfare and Health).

Gissler, Mika, Veli-Matti Ulander, Elina Hemminki and Anja Rasimus. 1996. Declining induced abortion rate in Finland: Data quality of the Finnish abortion register. International Journal of Epidemiology 25(2):376-80.

Haavio-Mannila Elina and Osmo Kontula. 2001. Seksin trendit meillä ja naapureissa. [Sex trends in Finland and in neighboring countries] (in Finnish). Helsinki: WSOY. 
Ingerslev, Olaf. 2001. Sundhedsforhold blandt indvandrere. [Health conditions among immigrants]. In: Integration i Danmark omkring ärtusindskiftet, edited by GV Mogensen and PC Matthiessen, pp.230-232. Aarhus: Aarhus Universitetsforlag.

Knudsen, Lisbeth B. 2002. Induced Abortion and Family Formation in Europe. In: Family Life and Family Policies in Europe, Volume 2, Problems and Issues in Comparative Perspective, edited by Franz-Xaver Kaufmann, Anton Kuisten, Hans-Joachim Schulze and Klaus Peter Strohmeier. Oxford: Clarendon Press.

Knudsen, Lisbeth B. (editor). 2001. Induced Abortion in the Nordic Countries. Research Report 22. Odense: Danish Center for Demographic Research.

Knudsen, Lisbeth B., Mika Gissler, Soley S. Bender, Claus Hedberg, Ulla Ollendorff, Kajsa Sundström, Kristiana Totlandsdal and Sigridur Vilhjalmsdottir. 2003. Induced Abortion in the Nordic Countries - with special emphasis on young women. Acta Obstetricia Gynecologica Scandinavia (In press).

Kontula, Osmo and Elina Haavio-Mannila. 1995. Sexual Pleasures: Enchancement of Sex Life in Finland, 1971-1992. Aldeshot: Dartmouth.

Kosunen, Elise. 1996. Adolescent Reproductive Health in Finland: Oral Contraception and Abortions from the 1980s to the 1990s. University of Tampere.

Kosunen, Elise, Andres Vikat, Mika Gissler and Matti Rimpelä. 2002. Teenage pregnancies and abortions in Finland in the 1990s. Acta Obstetricia Gynecologica Scandinavia. (In press.)

Krebs, Lone, Anne M. Johansen and Karin Helweg-Larsen. 1997. Registrering af provokerede aborter i 1994. En sammenligning af data fra Abortregistret og Landspatientregistret [Reporting of induced abortions in 1994. A comparison between the data in the Registry of Legally Induced Abortions and the National Patient Registry]. Ugeskrift for Laeger 159(11):1607-11.

Kulczycki, Andrzej, Malcolm Potts and A. Rosenfeld. 1996. Abortion and fertility regulation. Lancet 347/9016:1663-8.

Leridon, Henri. 1999. Les nouveaux modes de planification de la famille en Europe. [New methods of family planning in Europe.] In: European populations: unity in diversity, edited by D. van de Kaa, pp. 51-76. Dordrecht: Kluwer Academic.

Lottes, Ilse and Osmo Kontula (editors). 2000. New views on sexual health - the case of Finland. Publications of the Population Research Institute, series D 37. Helsinki: The Population Research Institute, The Family Federation of Finland.

Mandelin, Matti A. 1997. Pregnancy termination - situation in Finland. Acta Obstetricia Gynecologica Scandinavia 76/suppl 164: 51-3.

Meldbye, M. and R. Biggar. 1992. Interactions between persons at risk for AIDS and the general population in Denmark. American Journal of Epidemiology 135(6): 593-602.

NIDI. 2002. Personal communication to Lisbeth B. Knudsen at a meeting at NIDI, 16th October 2002.

Osler, Mogens. 1991. Svangerskabsforebyggende metoder og deres effektivitet. [Contraceptive methods and their efficacy] Ugeskrift for Laeger 1991; 153:562-5.

Osler, Mogens, Henry P. David, Janine Morgall and Niels Kristian Rasmussen. 1990. Family planning services delivery. Danish Experience. Danish Medical Bulletin 37(1):95-105.

Paajanen Pirjo. 2002. Perhebarometri 2002. Saako haikara tulla käymään? Suomalaisten lastenhankinnan ihanteet ja todellisuus. [Family Barometer: May the stork visit us? The ideals and reality of childbearing among Finns].(in Finnish). Väestöliitto, Väestöntutkimuslaitos, katsauksia E 14. Helsinki: Väestöliitto.

Rasch, Vibeke. 2002. Contraceptive failure-results from a study conducted among women with accepted and unaccepted pregnancies in Denmark. Contraception; 66(2):109. 
Rasch, Vibeke, Lisbeth B.Knudsen and Hanne Wieland. 2001. Pregnancy planning and acceptance among Danish pregnant women. Acta Obstetricia Gynecologica Scandinavia $80(11): 1030-5$

Sosiaali- ja terveysalan tutkimus- ja kehittämiskeskus. STAKES (National Research and Development Centre for Welfare and Health). 2002. http://www.stakes.fi/kouluterveys/nettinuori/ (In Finnish)

Ung 99. 1999. Young 99- a Sexual Profile. Vol. 1. Frederiksberg: Forebyggelsessekretariatet, Frederiksberg Hospital. (In Danish).

Vikat, Andres. 2002. Fertility in Finland in the 1980s and 1990s: Analysis of Fertility Trends by Age and Parity. Yearbook of Population Research in Finland 38:159-278. Helsinki: The Population Research Institute, The Family Federation of Finland.

Vikat, Andres, A. Rimpelä, Elise Kosunen and Matti Rimpelä. 2002. Sociodemographic differences in the occurrence of teenage pregnancies in Finland 1987-1988: a follow up study. Journal of Epidemiology and Community Health 2002; 56(9): 659-68.

Wielandt, Hanne and Lisbeth B. Knudsen.1997. Sexual activity and pregnancies among adolescents in Denmark - trends during the eighties. Nordic Sexology 15/2:75-88.

World Health Organization: Health For All -database. Available at: http://www.euro.who.int/hfadb (as accessed 11th October 2002). 